\title{
Atravesando la espesura de la ciudad: vida cotidiana y barreras de accesibilidad de los habitantes de la periferia urbana de Santiago de Chile ${ }^{1}$
}

\author{
Paola Jirón² y Pablo Mansilla ${ }^{3}$
}

\begin{abstract}
RESUMEN
El presente trabajo genera una aproximación a la comprensión de la exclusión social desde la movilidad cotidiana urbana por medio del estudio de la accesibilidad. Este enfoque teórico-metodológico permite evidenciar las múltiples barreras de accesibilidad que los viajeros encuentran diariamente en sus trayectos por la ciudad, las cuales van dando una "espesura" a la experiencia del tiempo-espacio. El documento primero contrasta las conceptualizaciones tradicionales de accesibilidad, posteriormente genera una propuesta para su análisis en la vida cotidiana a través de métodos etnográficos, y a modo de ejemplo, presenta dos casos de viajeras desde el sector norte de la ciudad de Santiago, una de ingresos medio bajos y otra de ingresos altos. Los resultados permiten identificar dicha espesura en las barreras de accesibilidad y cómo estas se conjugan para dar cuenta de la complejidad que las personas enfrentan para acceder a las oportunidades de la ciudad, las estrategias que emplean y las diversas formas de exclusión urbana que a partir de ellas se desprenden.
\end{abstract}

Palabras clave: Movilidad, accesibilidad, barreras, espacialidad, vida cotidiana.

\begin{abstract}
This paper presents an approximation of social exclusion from the point of view a daily mobility and through the study of accessibility. This theoreticalmethodological approach permits the documentation of multiple accessibility barriers that commuters confront daily on their commutes through the city. These barriers generate a sort of "weight" to the time-space experience. The document first contrasts traditional conceptualizations of accessibility and then proposes a way to analyse this in daily life using ethnographic methods, and provides two case studies of female commuters living in the Northern part of Santiago, one who is middle-low income and the other who is high income. The results identify the way in which accessibility barriers can be compounded resulting in difficulty in accessing opportunities in the city, the strategies they employ and the diverse forms of social exclusion that can emerge.
\end{abstract}

Key words: Mobility, Accessibility, Barriers, Spatiality, Daily Life.

1 Proyecto FONDECYT No 1090198. Artículo recibido el 27 de septiembre de 2012, aceptado el 24 de marzo de 2013 y corregido el 30 de julio de 2013.
2 Instituto de la Vivienda, Facultad de Arquitectura y Urbanismo, Universidad de Chile (Chile). E-mail: paolajiron@uchilefau.cl

3 Instituto de la Vivienda, Facultad de Arquitectura y Urbanismo, Universidad de Chile (Chile).

E-mail: pablo.manq@gmail.com 
El presente artículo tiene como propósito cuestionar las formas tradicionales que se han utilizado para abordar la accesibilidad en la ciudad desde el urbanismo, la ingeniería y la geografía. Para esto se propone una discusión de carácter epistemológico que se sustenta sobre dos giros: el espacial y el de movilidad en las ciencias sociales. El primero es útil para abordar el estudio del espacio y de la ciudad, como productos sociales y como resultantes de las prácticas sociales; y mediante el segundo, se discute la necesidad de integrar una noción espacio-temporal sobre la ciudad, de carácter relacional, que integre la forma en que se desenvuelven las prácticas móviles de la sociedad.

La literatura vinculada a estos temas, sobre todo desde el Reino Unido, indica que el transporte, la movilidad y específicamente la accesibilidad han sido reconocidos como aspectos significativos de procesos de desigualdad y exclusión social en la ciudad, analizando la vinculación con políticas públicas (SEU, 2003; Church et al., 2000), así como las dimensiones de la accesibilidad (Cass et al., 2005;) la sustentabilidad (Farringdon 2007), la planificación del transporte y sus impactos sociales (Jones \& Lucas 2012; Lucas 2009, 2012), o el reconocimiento la diferenciación espacial y social (Preston \& Raje 2007) ${ }^{4}$. Dentro de los factores que ejercen mayor incidencia en este proceso incluyen por un lado, aquellos vinculados a aspectos socioeconómicos y culturales de los individuos como ingreso, edad, género, etnia, ciclo de vida o discapacidad, y por otro aquellos vinculados a la infraestructura de accesibilidad como la provisión y disponibilidad de transporte público o privado y las condiciones que la estructura urbana presenta. Lo que aún no ha sido suficientemente investigado según Lucas (2012) tiene relación con cómo sucede esta exclusión, cómo se vinculan ambos factores, cómo la viven los habitantes urbanos, y cuáles son sus consecuencias en términos de los estilos de vida y oportunidades de los individuos, así como los efectos más amplios en la sociedad.

\footnotetext{
4 Ver Cebolleda 2009 para el caso de Barcelona, España.
}

Cuando se reconoce la accesibilidad como uno de los principales aspectos de la exclusión social en la ciudad, las intervenciones urbanas intentan aumentar la dotación de transporte como una forma de solucionar el problema 5 . Sin embargo, un análisis detenido de las prácticas de movilidad cotidiana revela que si bien el transporte puede ser un gran obstáculo para la accesibilidad, es necesario generar una aproximación a otros tipos de barreras, como las que se presentan más adelante, que den cuenta de la multiplicidad de obstáculos que las personas enfrentan cotidianamente, comprendiendo los ritmos, rutinas y hábitos propios de la vida diaria que dan una "espesura" a la accesibilidad.

El concepto de espesura es usado en este trabajo como una metáfora que permite dar cuenta de la densidad de barreras de accesibilidad que adquiere la movilidad en la vida cotidiana. Cuando las barreras se encuentran concentradas, entrelazadas y muy juntas unas de otras, generan que la movilidad se torne más pesada y difícil de resolver. De esta forma, la experiencia espacio-temporal de la movilidad cotidiana urbana no siempre es fluida, ya que se encuentra condicionada por diversos factores.

Al ser estudiados en detalle desde la perspectiva de la movilidad cotidiana urbana (Cass et al., 2005; Elliot \& Urry 2010; Jirón, 2012), los sistemas de transporte pueden llegar a ser considerados deficientes pero no necesariamente la principal barrera de accesibilidad. Esto se debe a que la movilidad implica algo más que viajar desde un punto $\mathrm{A}$ hasta un punto B. Citando a Miralles (2002), Cerda y Marmolejo (2010) argumentan que el estudio de la movilidad en investigación urbana, ha sido comúnmente entendida como sinónimo de transporte, predominando un enfoque fundamentado sobre la causalidad que ha centrado su mirada en la influencia de un factor a partir de otro, situación que los autores denominan como una mirada urbanística o transportística: "la mirada urbanística se ha ocupado de estudiar cómo la estructura física de la ciudad produce la demanda de movili-

\footnotetext{
5 A esto se le denomina Accessibility planning, ver Lucas 2006.
} 
dad", mientras que la mirada transportística analiza "cómo la oferta de transporte induce la localización de actividades" (Cerda y Marmolejo, 2010: 7).

Comprender la movilidad implica también entender lo que ocurre durante la práctica cotidiana de moverse en la ciudad, y a través de ella se pueden comprender las capacidades que tienen las personas para acceder a bienes, servicios, actividades, relaciones y lugares (Kaufmann et al., 2004; Jirón et al., 2010; Gutiérrez, 2009). Cuando un sujeto se encuentra imposibilitado de acceder a las oportunidades existentes, se encuentra excluido de poder participar socialmente. De esta forma, el análisis de la estructura y disposición territorial que presentan los sistemas de transporte adquirirá profundidad y relevancia en la medida en que se observe también el modo en que estas otorgan experiencias a las personas en su transitar a través de la ciudad.

El concepto de accesibilidad se ha vuelto un término polisémico, producto de que las diversas miradas que se han abocado a su estudio (arquitectura, geografía, ingeniería del transporte, entre otras disciplinas) han centrado su interés en distintos aspectos de este concepto (Kaufmann \& Jemelin 2004). Cerda y Marmolejo (2010), identifican tres formas conceptuales mediante las cuales se ha enfrentado el estudio de accesibilidad: la concepción física, la económica y la social. La primera concepción de carácter física, ha centrado su interés en la localización de los elementos dispuestos en el espacio, analizando aspectos como la contigüidad espacial, la difusión de actividades y las innovaciones en el espacio. En segundo lugar, la visión económica, centra su análisis en los beneficios que posee para un individuo el uso óptimo de su tiempo e ingresos. De esta forma, según Cerda y Marmolejo (2010) la accesibilidad económica se entiende como "la utilidad que reporta al hogar o firma el visitar actividades propias de su quehacer, y por atracción del beneficio económico por las visitas que reciben de su entorno" (Cerda y Marmolejo, 2010: 7). En tercer lugar, la visión social de la accesibilidad se encuentra integrada a la noción de motilidad, la que se refiere principalmente a la capacidad personal de los individuos o de un grupo social para moverse a través del espacio. Para el estudio de la motilidad se integran en la discusión las competencias de los individuos para enfrentar las barreras de accesibilidad, y las formas de apropiación del espacio que estos desarrollan para moverse (Kaufmann et al., 2004; Cass et al. 2005).

El presente trabajo aporta a esta discusión proponiendo una definición de accesibilidad cercana a las conceptualizaciones sociales. Asimismo, aporta mediante la propuesta de utilización de metodologías cualitativas para el análisis de la accesibilidad, específicamente por medio de un enfoque etnográfico. De forma general, el enfoque propuesto busca entender la accesibilidad, analizando la relación entre experiencia de accesibilidad e infraestructura de accesibilidad. Para lo cual analiza el modo en que las espesuras de las barreras de accesibilidad inciden sobre la experiencia de la vida cotidiana, así como también, el modo en que las personas desarrollan tácticas y estrategias para subvertir los condicionamientos de estas barreras. De esta forma, se busca argumentar que este enfoque permite obtener herramientas para el análisis de las experiencias de movilidad cotidiana, por medio de las cuales es posible identificar una espesura de las barreras de accesibilidad que comúnmente no logran ser capturadas por los enfoques tradicionales. Asimismo, permiten identificar, a través de las prácticas de movilidad, el modo en que en algunos casos, la combinación de la infraestructura urbana existente y las condiciones socioeconómicas y socioculturales conllevan a la exclusión social de un grupo de personas o de un individuo.

Tales aportes han sido obtenidos a partir de los resultados del proyecto de investigación en el cual se enmarca el presente estudio, desarrollado entre los años 2009 al 2012, que contempló el acompañamiento etnográfico, y el análisis de más de 70 casos de estudio en la Región Metropolitana, seleccionados a partir de sus características socioculturales (Ver Figura $N^{\circ} 1$ ) y de localización según área central, pericentral, periférica y extraperiférica. Con el fin de aprehender las experiencias de movilidad se adoptó un método etnográfico, en el cual se acompañó durante sus desplazamientos cotidianos a diversos viajeros urbanos de ingresos bajos, medios y altos, que habitan diversos sectores 
de la ciudad, utilizando el método de sombreo (Jirón, 2010). El sombreo se trata de un acompañamiento a los participantes de investigación de manera individual en sus rutinas cotidianas, donde el investigador observa la manera en que los participantes llevan a cabo su práctica, a modo de sombra.

En la primera parte del documento se contrastan las conceptualizaciones tradicionales de accesibilidad, las que relevan principalmente restricciones físicas y locacionales que impone el espacio para el transporte, con aquellas que centran su interés en las condiciones y barreras personales que deben enfrentar cotidianamente los individuos en la ciudad, y que dan cuenta de la "espesura" de las barreras de accesibilidad. Luego se presenta la forma en que la experiencia de movilidad se vincula con las nuevas discusiones en torno al giro espacial y el giro de la movilidad en las ciencias sociales y su implicancia en la comprensión de la accesibilidad. A partir de esto, se presenta una propuesta teórico-metodológica para el análisis de la accesibilidad en la vida cotidiana, utilizando un enfoque etnográfico. Posteriormente, se presentan, a modo de ejemplo, experiencias de movilidad de dos viajeras que residen en la extraperiferia de la Región Metropolitana de Santiago de Chile, específicamente en la comuna de Colina, de ingresos bajos y altos, que viajan por medio de transporte público y privado. Los resultados permiten identificar la forma en que las barreras de accesibilidad dan cuenta de las dificultades que las personas enfrentan para acceder a las oportunidades de la ciudad y las diversas formas de exclusión urbana que a partir de ellas se desprenden.

\section{Accesibilidad y transporte: el espacio físico y las restricciones para la accesibilidad}

La literatura sobre movilidad, principalmente aquella que hace referencia a estudios sobre transporte en Europa y Estados Unidos, proporciona varias formas para medir la accesibilidad utilizando un enfoque de oportunidades espaciales (Miller, 1999, 2005, 2006; Baradaran \& Ramjerdi, 2001) incorporando la experiencia de barreras de transporte (Hine y Mitchel, 2001), la planificación de accesibilidad (Lucas, 2006, 2012); la movilidad virtual (Kenyon et al., 2002; Kenyon et al., 2003; Kenyon, 2006); y la accesibilidad directa o indirecta (Hine \& Grieco, 2003). En cuanto a la definición económica de accesibilidad, es posible argumentar que si bien la mayoría de los autores concuerdan en que no existe una medida universal para el análisis de la accesibilidad, esta es a menudo comprendida como conectividad, ya sea desde el lado de la oferta o de la demanda. En esta definición, Miller (1999) clasifica tres tipos de enfoques: (i) enfoque orientado a las limitaciones, (ii) medidas de atracción de accesibilidad y (iii) beneficios de transporte, los cuales generalmente son consideradas como medidas de maximización. Gran parte de los modelos de transporte se basan en el último enfoque mencionado, el cual se calcula en términos de costo beneficio, modelos de uso intensivo de datos y unidades monetarias de costo. Sin embargo, de acuerdo a Axhausen et al. (2002), investigaciones relacionadas a los procesos mediante los cuales los pasajeros distribuyen su tiempo revelan que el más popular de los paradigmas, el de la maximización de la utilidad, es incompleto debido a la falta de comprensión de los ritmos, rutinas y hábitos propios de la vida diaria.

Adicionalmente, las conceptualizaciones tradicionales de accesibilidad desde los estudios de transporte han privilegiado contextualizar sus análisis a partir de la dimensión locacional de los elementos materiales presentes en el espacio geográfico, lo que también ha sido definido por Cerda y Marmolejo (2010), como enfoque físico de accesibilidad. En general estas concepciones de accesibilidad se encuentran fundamentadas por los postulados de la Geografía Regional y Positivista de las Escuela Alemana y Francesa, que tal como mencionan Higueras (2003), Camagni (2005) y Ramírez (2007), se despliegan desde el siglo XIX hasta la década de 1980, y encuentra entre sus principales exponentes a Walter Christaller, August Lösch, Johann Heinrich Von Thunen y otros autores. Estos exponentes trataron de establecer teorías, modelos y leyes generales en torno a la localización espacial óptima de los elementos en el espacio geográfico. El éxito y trascendencia de estos modelos encuentra su respuesta en que las 
aplicaciones resultaron ser bastante efectivas en la práctica, debido a que su generalidad permite replicar su estructura analítica en cualquier lugar. En el campo de investigación sobre accesibilidad, esta medida tradicional ha sido ampliamente aceptada y utilizada para decisiones de políticas y planificación urbana, debido a que resulta eficaz, científica y clara para la evaluación de planes y proyectos (Cerda y Marmolejo, 2010). Sin embargo, tal como lo menciona Ramírez (2007) estos enfoques presentan severas limitaciones para generar un acercamiento más concreto a la realidad socioespacial, ya que han tenido que asumir el costo de eliminar de sus análisis el rol de los sujetos y los grupos sociales en la producción y transformación del espacio: "la Geografía Regional Espacialista ha logrado persistir, debido a que ha deshumanizado la región al analizarla sin agentes, con base en modelos que suponen pueden aplicarse a todos los contextos y todas las situaciones" (Ramírez, 2007:120).

A partir de esta concepción de espacio homogéneo e isotrópico, los indicadores utilizados en los estudios de accesibilidad comúnmente han sido desarrollados a partir de las posibilidades de desplazamiento que genera la red vial de la ciudad. De esta forma, la red vial se constituye en la columna vertebral que estructura los desplazamientos, condicionando sus posibilidades de interactuar con otros espacios de la ciudad. En base a esta idea, Varela menciona que se puede pensar que la red vial alcanzará su máxima funcionalidad cuando logre reducir al mínimo los costes de desplazamiento a través de ella, lo que incidirá en el "bienestar social, dotando de un adecuado servicio de comunicación a todos los habitantes de la región, aumentando el grado de participación en la comunidad y favoreciendo el establecimiento de nuevas actividades económicas" (Varela, 2004: 346). El presente artículo, argumenta que si bien este enfoque de accesibilidad nos permite entender parte de las limitaciones físico-espaciales que las personas deben enfrentar en la ciudad, presenta una serie de limitaciones para entender la complejidad de la exclusión social asociada a la movilidad.

Es necesario remarcar que la investigación del comportamiento de viaje ha mostrado grandes avances desde el trabajo de Hanson (Hanson \& Hanson, 1980, 1981), el cual estableció una clara conexión entre comportamiento de viaje y actividad cotidiana de viaje, además de conceptualizar al viaje como algo más que desplazarse desde un punto $A$ hasta un punto B. De acuerdo a Law (1999), se ha realizado un importante trabajo para poder explicar las relaciones entre viaje/desigualdad de género ${ }^{6}$ y discapacidad/transporte. Hoy en día, el análisis sobre accesibilidad se lleva a cabo mediante datos cuantitativos, generando modelos de vida cotidiana y movilidad, por ejemplo utilizando bitácoras de viaje para determinar el cambio los ritmos y rutinas de viaje (Axhausen et al., 2002), o enfatizar el uso de sistemas de información geográfica para entender y visualizar el tiempo y espacio (Kwan et al., 2003; Kwan \& Lee, 2003); o redes sociales (Ohnmacht, 2006), al utilizar mayormente un enfoque de gravedad y oportunidades basado en las oportunidades espaciales disponibles para los pasajeros. Si bien estos análisis son necesarios y de gran utilidad para comprender la suma de patrones sobre el comportamiento de viaje, aun no descifran la especificidad de la experiencia de viaje para distintos grupos de personas, así como la forma en que esta experiencia afecta el acceso a beneficios urbanos y la forma en que esta práctica se relaciona con otros aspectos del quehacer urbano. De esta manera, los estudios en comportamiento de viaje podrían ampliarse si se complementaran con una investigación más detallada sobre las experiencias de movilidad cotidiana.

\section{Hacia una conceptualización de la accesibilidad desde la experiencia de la movilidad cotidiana urbana}

De forma general, durante las últimas décadas las ciencias sociales han experimentado diversos avances en las discusiones epistemológicas sobre la espacialidad social, que permiten enriquecer la conceptualiza-

\footnotetext{
6 Para más detalles sobre la evolución en el estudio sobre transporte y género en las sociedades occidentales, ver Law (1999), Hanson (2010), Grieco \& Mcquaid (2012)
} 
ción de accesibilidad. En este sentido, existen dos giros teóricos interesantes de profundizar para comprender otras formas en que la accesibilidad incide en la vida cotidiana: el giro cultural y el giro de la movilidad.

El primer giro en las ciencias sociales, se encuentra dado por una profundización de los aspectos culturales en los estudios espaciales, a través del cual se ha intentado recuperar la condición del sujeto y de los grupos sociales en la producción del espacio, ahondando en el modo en que sus prácticas, sus percepciones y valoraciones se materializan espacialmente, no tan solo en la dimensión física y tangible del espacio, sino también, como una construcción subjetiva guiada por las percepciones y significaciones que las personas generan del mundo (Claval, 2002; Gallastegui, 2009). Estos planteamientos permiten ampliar la discusión espacial en las ciencias sociales, comprendiendo el modo en que los diversos procesos políticos, económicos, sociales y culturales configuran el espacio en diversas escalas, que van desde lo global a lo cotidiano, o viceversa. De esta forma, el espacio se vuelve una categoría de análisis que permite introducirse en una dimensión fundamental de la vida social.

Un segundo aspecto interesante de incorporar en la discusión epistemológica que se ha desarrollado en esta materia, tiene relación con el giro de la movilidad (Elliot \& Urry, 2010; Sheller \& Urry, 2006; Cresswell, 2010) que ha venido siendo ampliamente desarrollado durante la última década, y que ha permitido incorporar una mirada transformadora en la investigación socioespacial. La movilidad cotidiana urbana puede ser entendida como "aquella práctica social de desplazamiento diario a través del tiempo-espacio urbano que permite el acceso a actividades, personas y lugares" (Jiron et al., 2010: 24). Esta idea permite comprender la movilidad como un enfoque para entender las consecuencias sociales, económicas, culturales y espaciales que genera sobre la conformación del espacio urbano y los distintos tipos de experiencia de sus habitantes.

En este sentido, Gutiérrez (2009), agrega que más allá de las condiciones materiales que inciden en el movimiento de las personas en la ciudad, la movilidad es el "resultado de y condición de la inserción de un grupo en un contexto social, definido por factores físicos, locacionales, económicos, regulatorios, culturales, de género, étnicos, entre otros" (Gutiérrez, 2009: 2). En contraste a esta mirada los estudios clásicos que se han generado y han prevalecido en la geografía y la ingeniera del transporte han estudiado solo la dimensión material del viaje, en términos de los patrones estructurales, dejando de lado las condiciones que surgen producto de la experiencia y aquellas que son vivenciadas por las personas en sus movimientos en la ciudad. Gutiérrez (2009), menciona que la accesibilidad puede ser considerada como una "práctica que conjuga deseos y necesidades de desplazamiento y capacidades de satisfacerlos" (Gutiérrez, 2009: 2).

Es en este contexto, autores como Avellaneda (2008), Gutiérrez (2009), Jirón (2009), Jouffe \& Lazo (2010), Lazo (2008) o Lenntorp (1991), desarrollan la idea que la accesibilidad se encuentra relacionada con las condiciones personales que los individuos o grupos sociales poseen para poder moverse, siendo las características físicas del espacio y la red de transportes parte importante de los factores que limitan la accesibilidad, pero no los únicos a considerar al momento de ampliar una discusión sobre exclusión y movilidad. De esta forma, los autores mencionan que la movilidad y el concepto de acceso se presenta como un marco conceptual interesante para profundizar en los procesos de exclusión social urbana a partir de las relaciones de los individuos con el espacio y del espacio con los individuos, para lo cual se apoyan sobre instrumentos de corte cualitativo que les permiten profundizar sobre las formas en las que se habita y se mueve en la ciudad. Al ser entendida como un nivel de conectividad, Church, Frost et al. (2000) señalan que la accesibilidad es solo una dimensión de la exclusión social y que un alto índice de accesibilidad no significa que la gente pueda llegar a beneficiarse de ella.

Pese a que la manera de analizar la accesibilidad en los enfoques físicos o económicos ha resultado ser de gran utilidad para reconocer las implicancias de la movilidad en la exclusión social, esta presenta problemas tales como un enfoque verticalista que no presta adecuada atención a las reales prácti- 
cas individuales que se llevan a cabo diariamente o a la forma en que las personas hacen uso de la movilidad para propósitos ajenos al transporte. Asimismo, tal como lo sugiere Cass et al. (2005), no existen muchas referencias a la manera en que las personas acceden a sus redes de relaciones ${ }^{7}$. Por esta razón, Hine \& Grieco (2003: 300) sugieren establecer una diferencia entre accesibilidad directa e indirecta, donde la primera hace referencia a la "habilidad que las personas tienen para planificar y llevar a cabo viajes en medios públicos o privados sujetos a presupuesto y costo" mientras que la segunda implica "el punto hasta el cual los individuos o grupos de personas pueden confiar en sus vecinos $u$ otras redes de apoyo para acceder a bienes e instalaciones a su nombre, sujetos a tiempo y presupuesto" (Hine \& Grieco, 2003: 300).

Por otro lado, un aspecto que explica la importancia de la movilidad es la gran influencia que tiene en la vida cotidiana de las personas, puesto que las vidas no quedan suspendidas durante el desplazamiento diario. El tiempo que se utiliza en desplazarse no es tiempo perdido, ya que diversas situaciones ocurren en los momentos móviles y en los espacios en que las personas se mueven, muchas veces otorgan significado y sentido de apropiación para los viajeros (Jirón e Iturra, 2011). Al mismo tiempo otorgan oportunidades, en el bus, metro, automóvil o desde estos espacios, para apropiarse y acceder a otras experiencias y oportunidades en la ciudad.

Así, para poder comprender la forma en que la movilidad influye en la exclusión social, y adaptando el trabajo de Cass et al. (2005), se propone aquí analizar la accesibilidad como la habilidad de negociar el tiempo y el espacio para cumplir con actividades cotidianas, mantener relaciones y generar los lugares que las personas necesitan para participar en sociedad. Si bien esta definición no captura todas las dimensiones de la exclusión social, entrega una mayor comprensión respecto de las implicancias de lo que significa estar conectado o desconectado, de las capa-

\footnotetext{
7 Salvo el trabajo de Carrasco (2011), Carrasco y Miller (2009) en Concepción, Chile
}

cidades que las personas tienen para entrar o salir, las consecuencias de ser excluido o el hecho de escoger donde vivir; de este modo, se observan los tipos de conexiones, de tiempo, espacio y de relaciones.

Un aspecto que se destaca en la definición planteada de accesibilidad es la negociación, ya que es en las intersecciones diarias de tiempo y espacio donde es más probable que ocurran conexiones y desconexiones, surjan problemas $u$ oportunidades y se expresen desigualdades. El concepto de "negociación" implica una interacción con otros, sean agentes, condiciones del contexto, y en este caso con las "barreras de accesibilidad". Cuando se enfrenta cada una de estas barreras, los viajeros deben negociar cómo enfrentarlas, en algunos casos las obvian, en otros las disminuyen, en otras simplemente las rechazan y subvierten. Esto implica que se establezca una organización de las propias condiciones, es decir, estrategias o tácticas para negociar con ellas. Las estrategias se refieren, a la manera en que los individuos y los grupos negocian espacio y tiempo para llevar a cabo las practicas, el mantenimiento de las relaciones y el acceso a los lugares que se consideran necesarias para la participación social normal (Jirón, 2009, citando a Cass et al., 2005). Mientras que las tácticas se refieren al modo en que las personas articulan acciones que permiten subvertir las barreras disciplinatorias, a diferencia de las estrategias, las tácticas son dispersas, efímeras e improvisadas, y responden a demandas concretas sobre una situación. Respecto al proceso de la negociación de acceso, las distintas formas en que este se ve restringido -debido a limitantes de carácter social, físico, económico o incluso ambiental- indican que la inaccesibilidad podría estar relacionada con la ubicación desigual de infraestructura o la presencia de un sistema de transporte público deficiente. Sin embargo, un acceso desigual también podría generarse a partir de factores como la existencia de relaciones de género dispares, ya sea dentro del hogar o en la sociedad, o barreras culturales que impiden la mezcla o encuentros entre distintos grupos sociales. Esto implica que diferencias sociales tales como género, edad, ingreso, habilidad, religión u origen étnico pueden Ilegar a generar experiencias diferenciadas de movilidad, las cuales podrían traducirse en accesibilidad 
restringida. De este modo, mejorar la accesibilidad involucra considerar factores que van más allá de la eliminación de barreras físicas o la creación de infraestructura, servicios y viviendas, ya que un incremento del transporte podría tener nefastas consecuencias en lo que refiere a exclusión social (Shove, 2002).

\section{Barreras y espesuras de accesibilidad: propuesta teórico-metodológica para su aproximación}

La geografía del tiempo fue pionera durante la década de 1970 e introdujo el vínculo indisoluble entre tiempo y espacio. En su elaboración del mapeo tiempo espacio, Hägerstrand (1970) desarrolló dos de los principales obstáculos en cuanto a la accesibilidad, tiempo y espacio, a través de tres tipos barreras de tiempo espacio: acoplamiento, capacidad y autoridad ${ }^{8}$. Sin embargo, tiempo y espacio como nociones "absolutas", no capturan completamente la complejidad de los obstáculos presentes en la movilidad. Church et al. (2000) identificaron siete dimensiones que actúan como barreras en cuanto a accesibilidad, estas son limitantes de tipo físico, geográfico, actividades e instalaciones, económico, tiempo, temor y espacio. Kenyon et al. $(2002,2003)$ sugiere nueve dimensiones de exclusión social que influyen en la falta de movilidad, a saber: económicas, espacio vital, movilidad, políticas de organización, personal, políticas personales, redes sociales, de sociedad y temporales. Por su parte, Cass et al. (2005) sintetizaron estas barreras en cuatro dimensiones clave respecto al acceso, estas son limitaciones de carácter financiero, físico, de orden y temporal. Law

\footnotetext{
8 Las limitaciones de acoplamiento definen dónde, cuándo, y por cuánto tiempo las personas pueden reunir otras personas, herramientas y materiales para producir, consumir y negociar; las limitaciones de capacidad son aquellas que limitan las actividades de las personas debido a factores físicos (distancia) o biológicos (dormir, comer); las limitaciones de autoridad hacen referencia a un área de control donde los elementos y los eventos están bajo el control de ciertos individuos o grupos que fijan límites de acceso (donde se requiere un pago, invitación, ceremonia o lucha). Esta suma de limitaciones interactúan entre sí (Hägerstrand, 1970).
}

(1999) también postula habilidades y tecnología como obstáculos de movilidad.

Para esta investigación, la accesibilidad a las prácticas diarias, relaciones y lugares es analizada de acuerdo a barreras financieras, físicas, organizacionales, temporales, de habilidades y tecnológicas. Las barreras de tipo financiero pueden afectar, por ejemplo, el costo de utilizar distintos medios de transporte, la capacidad o disponibilidad para pagar peaje, estacionamiento, por ejemplo. Las dimensiones físicas pueden estar relacionadas con la distancia recorrida, con el aspecto físico o condición de los espacios con los que se interactúa, como por ejemplo calles, aceras, paraderos de buses, buses, metros, andenes, caminos para bicicletas o parques, o con la facilidad de orientación que ofrece el espacio, entre otros. Las restricciones organizacionales están relacionadas con las actividades múltiples que las personas Ilevan a cabo regularmente para coordinar su vida diaria, estas tareas incluyen realizar compras, asistir a servicios básicos (salud, educación, etc.), el pago de cuentas, el acceso al lugar de trabajo, etc., muchas veces estas actividades están entrelazadas con obligaciones como las familiares, especialmente hijos, o amistades. Las dimensiones temporales involucran la forma en que el día, la noche, las estaciones, los horarios de apertura y la duración de los viajes afectan la toma de decisiones en lo que a movilidad se refiere. Las limitantes relacionadas a la habilidad hacen referencia a las capacidades que tienen las personas para desplazarse en formas específicas, por ejemplo, saber conducir o poseer una licencia de conducir, ser capaz de cambiar neumáticos, saber cómo montar una bicicleta, ser capaz de reparar una bicicleta o sentirse cómodo conduciendo una motocicleta. Las barreras de tipo tecnológico involucran la posibilidad y capacidad de utilizar tecnología, así como la disponibilidad de esta para ampliar o facilitar los viajes o sustituir la necesidad de realizar viajes físicos mediante el uso de internet o teléfonos móviles, entre otros.

Cada una de estas limitantes se ve alterada cuando se observa a través de condiciones socioculturales individuales o grupales que pueden ser de tipo etario, de género, étnico de etapa dentro del ciclo de vida, entre otros. Estas características socioculturales se con- 
sideran otro tipo de barrera que, además de condicionar todas las limitantes mencionadas anteriormente, tienen un gran impacto sobre las formas diferenciadas en que se experimenta la movilidad.

El Cuadro $N^{\circ} 1$, muestra estos tipos de limitantes para poder analizar, por ejemplo, en qué punto el acceso a movilización se ve afectado si un paradero de bus no se encuentra ubicado en un lugar adecuado. Esta complicación se agrava si personas mayores con dificultad para desplazarse se ven forzadas a minimizar o renunciar a utilizar un determinado medio de transporte. Asimismo, la disponibilidad de transporte en determinados momentos puede convertirse en un problema para gran parte de los usuarios, pero se convierte en limitante en el caso de mujeres o niñas adolescentes que temen por su seguridad cuando viajan solas de noche. Del mismo modo, una madre con un bebé en coche puede tener mayores dificultades debido a la conjunción de barreras físicas, temporales y organizaciones que hacen más difícil viajar.

El análisis de las barreras de accesibilidad permite comprender que la experiencia espacio-temporal adquiere una espesura específica cuando se observa el modo en que se desenvuelven las prácticas de movilidad urbana cotidiana. De esta forma, la espesura, término comúnmente utilizado para referirse a la fluidez de un líquido, permite referirse metafóricamente a la densidad de una ex- periencia móvil de los sujetos a través del espacio-tiempo. En aquellas experiencias en las cuales la accesibilidad se vuelve espesa, se argumenta que existe una multiplicidad de barreras significadas por las personas con mucho contenido y profundidad, que implican que su inserción en la movilidad encuentre un peso y un desgaste sobre las personas que requieren acceder a la ciudad y probablemente una experiencia de mayor exclusión social.

Así, cuando la espesura de las barreras de accesibilidad es más significativa, es posible identificar diversas configuraciones que remarcan en la experiencia de viaje la exclusión social. Ante las barreras de accesibilidad las personas no se posicionan tan solo como espectadores, sino que desarrollan estrategias y tácticas mediante las cuales negocian espacio y tiempo en torno a sus posibilidades. La negociación que realizan los viajeros urbanos no solo sucede todos los días, sino a cada instante del trayecto en un contexto de alta agilidad y movimiento. Las barreras reducen la capacidad de desarrollar estrategias para enfrentarlas y genera el despliegue de tácticas de negociación del tiempo espacio.

La "espesura de accesibilidad" da cuenta de una combinación de barreras que implica mucho más que su simple sumatoria en un momento dado del viaje. La espesura de las barreras de accesibilidad encuentra a lo menos tres características: se encuentran en

Cuadro $\mathrm{N}^{\circ} 1$

Marco de Accesibilidad desde la movilidad cotidiana

\begin{tabular}{|l|l|l|l|l|l|l|}
\hline \multirow{2}{*}{$\begin{array}{l}\text { Barreras/ } \\
\text { Dimensiones de } \\
\begin{array}{l}\text { Accesibilidad } \\
\text { Cotidiana }\end{array}\end{array}$} & \multicolumn{5}{|c|}{ Condiciones socioculturales } \\
\cline { 2 - 6 } & Financieras & Físicas & Habilidades & Temporales & Organizacionales & Tecnológicas \\
\hline $\begin{array}{l}\text { Actividades } \\
\text { (empleo, } \\
\text { educación, salud, } \\
\text { recreación ...) }\end{array}$ & & & & & & \\
\hline $\begin{array}{l}\text { Relaciones } \\
\text { Sociales (redes) }\end{array}$ & & & & & & \\
\hline $\begin{array}{l}\text { Lugares (móviles, } \\
\text { fijos, transientes) }\end{array}$ & & & & & & \\
\hline
\end{tabular}

Fuente: Jirón, 2009. 
constante devenir a lo largo del viaje; poseen una multiplicidad de combinaciones; y son multiescalares espacio-temporalmente.

La primera característica mencionada respecto al devenir de las barreras permite entender que las barreras de accesibilidad aparecen y desaparecen a lo largo de la experiencia de viaje, dibujando y desdibujando diversas espesuras de accesibilidad. En movimiento, las barreras van alternándose de forma aleatoria, construyendo diversos tipos de experiencias de movilidad.

La segunda característica de las espesuras de accesibilidad vinculada a la multiplicidad de las barreras, da cuenta del modo en que los sujetos deben enfrentar cotidianamente diversas configuraciones de barreras que inciden sobre la espesura de la movilidad; si bien es posible identificar barreras que se mantienen a lo largo del viaje, vinculadas a las condiciones socioculturales de los sujetos que van remarcando a lo largo del viaje las condiciones estructurales de la exclusión en la movilidad, como por ejemplo la condición de clase, género, etnia u otro tipo de subalternidad, las sub-barreras se van alternando de diversas formas a lo largo de los desplazamientos cotidianos en la ciudad.

La tercera característica vinculada a la multiescalaridad, explica el modo en que las barreras de accesibilidad pueden abarcar diferentes escalas espacio-temporales, otorgando diversas espesuras a la accesibilidad. Un grupo de barreras puede abarcar tan solo un punto específico dentro del trayecto de una persona, o pueden marcar la totalidad del viaje a través de la ciudad. Esta multiescalaridad implica que el transcurrir entre escalas no siempre es jerárquico, ya que a menudo se puede pasar desde una escala local, al nivel global en un segundo, constituyendo escalarmente de forma relacional o rizomática.

\section{Caso de estudio: espesura de accesibilidad en la extraperiferia de Santiago}

Los casos a estudiar se definieron en tres etapas; en la primera se dividió la ciudad de Santiago según el dinamismo de flujos en la ciudad utilizando los datos de la Encuesta Origen Destino (SECTRA, 2006) y el Censo 2002 (INE, 2002) por medio de los cuales se definieron las zonas de dinamismo según centro, pericentro, periferia y extraperiferia y se seleccionaron comunas de la ciudad que correspondían a estas zonas. En una segunda etapa se seleccionaron sectores dentro de las comunas representativas de estas zonas donde se pudiese encontrar hogares de ingresos bajos, medios y altos, según correspondía, en algunas zonas solo se pudo seleccionar sectores de ingresos bajos, en otros solo altos y en algunos los tres rangos. Finalmente, se seleccionaron miembros de hogares que tuvieran una movilidad activa (salir de su casa todos los días) que correspondieran a diversos grupos: hombres y mujeres, de diversas edades e ingresos. Con estos criterios se sombrearon 76 casos en 8 zonas de Santiago (Santiago centro, El Golf/Sanhattan, La Cisterna, Huechuraba/Conchalí, Las Condes, Maipú, La Florida, Puente Alto, Talagante y Colina).

Con el fin de detectar cómo se enfrentan cotidianamente las barreras en los viajes de los santiaguinos, se utilizó un enfoque etnográfico y específicamente la técnica del sombreo (Jirón 2010). La técnica del sombreo implica acompañar a los participantes de investigación en sus rutinas diarias, donde el investigador observa la forma en que los viajeros llevan a cabo su práctica. Sombrear prácticas de movilidad involucra una comprensión respecto a cómo se preparan para salir del lugar de residencia por la mañana, o cómo sobrellevan, por ejemplo, andar en un bus hacinado en horario de punta o manejar por la ciudad durante todo el día; el aburrimiento de esperar o el miedo de llegar tarde al hogar en la noche, dentro de muchas otras actividades. El etnógrafo obtiene una idea respecto a cómo se desarrolla cada viaje, el hogar, la situación socioeconómica, los aspectos culturales, al entrevistar a los participantes previo al proceso de sombreo. Sin embargo, nada se compara a la experiencia actual del viaje, por eso la efectividad del enfoque.

El viaje puede ser fotografiado, grabado (sonido o video) durante el proceso de sombreo. Técnicas similares han sido desarrolladas, incluyendo los "acompañamientos" de Kusenbach (2003) o Spinney (2009) o los 
diarios de viaje de Latham (2004) utilizados en investigación fenomenológica de las experiencias espaciales urbanas. La metodología aquí desarrollada ha probado ser adecuada para capturar experiencias de movilidad cotidiana en la ciudad de Santiago (Jirón, 2010), ya que puede verse como una manera apropiada de describir las prácticas cotidianas de individuos, dada su flexibilidad y posibilidad de penetrar, por medio de descripción profunda y multifacética, en las rutinas diarias de habitantes urbanos móviles.

El principal producto de este seguimiento es el relato etnográfico, utilizado aquí como dato de análisis. En este sentido, los relatos etnográficos y su análisis no se centraron exclusivamente en los viajes durante los cuales las personas fueron acompañadas por las y los investigadores, sino que integraron en la narración el contexto en el cual estos viajes se sitúan: las explicaciones que las personas generan respecto a sus decisiones; sus quejas, frustraciones, ideas sobre cómo podría mejorar su forma de moverse y su vida en general; los preparativos para el viaje, los acuerdos con otros que facilitan o permiten la realización de esos viajes, obstáculos en su organización cotidiana o respecto a sus expectativas, las comparaciones con el pasado propio y ajeno en las formas de moverse, recuerdos gatillados por las conversaciones o lugares durante los viajes, entre otros aspectos.

En el análisis de los relatos etnográficos provenientes del acompañamiento de viajeros urbanos, se identificó cómo suceden y se enfrentan a las barreras de accesibilidad y cómo son vividas por los viajeros. Una vez terminado el trabajo de terreno se puede constatar que las barreras de accesibilidad en general no se viven de manera aislada, al contrario son dinámicas, muchas veces simultáneas y multiescalares, tal como se describen a continuación.

Para explicar la forma en que se enfrentan las barreras de accesibilidad y se configura su espesura, se presentan a continuación dos casos de viajeras de la extraperiferia metropolitana, específicamente de la comuna de Colina. Esta comuna se ubica en la zona de la ex-

Figura $\mathrm{N}^{\circ} 1$

Casos de estudio en la comuna de Colina

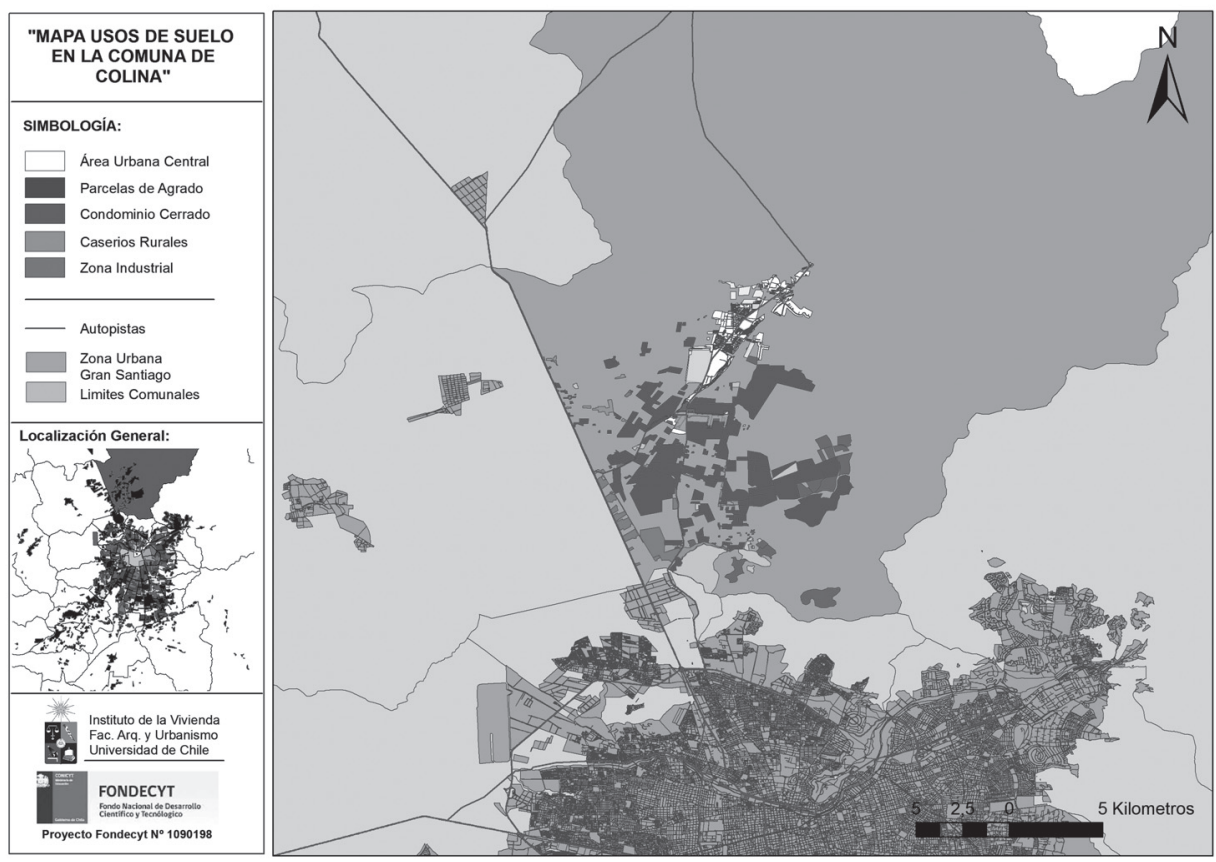

Fuente: Elaboración propia. 
Figura $\mathrm{N}^{\circ} 2$

Mapa tiempo espacio del viaje de Sofía

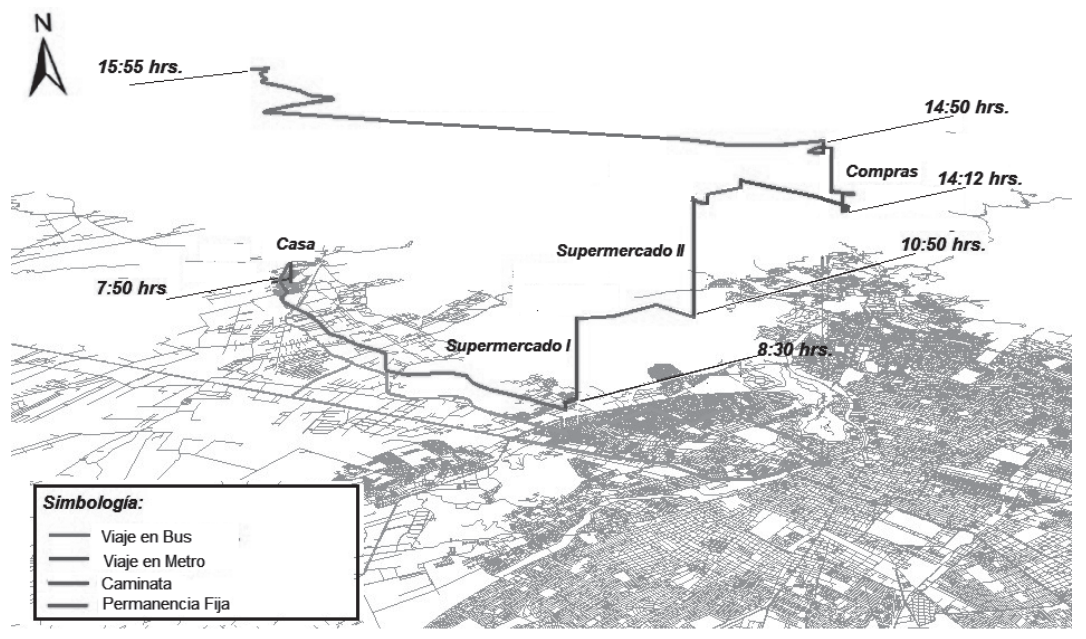

Fuente: Elaboración propia.

traperiferia norte de la ciudad de Santiago, en zonas predominantemente rurales pero que han experimentado un rápido proceso de urbanización durante los últimos años, ya que por un lado incorporó un número importante de viviendas sociales en la década de los 90 en sectores más poblados de la comuna, y en áreas más rurales por parcelas de agrado y condominios cerrados (Mansilla, 2011) (ver Figura $\mathrm{N}^{\circ} 1$ ). Los casos de estudio seleccionados corresponden a una viajera de ingresos medios-bajos, que se desplaza en transporte público y una viajera de ingresos altos que se desplaza en automóvil.

Barreras de Accesibilidad en los Viajes desde la Extraperiferia al Centro de Santiago bus: ingreso medio bajo (ver Figura $\mathrm{N}^{\circ} 2$ ). El mapa tiempo-espacio (Mapa 2) que se presenta a continuación explica el desplazamiento de Sofía a lo largo del día. El eje horizontal muestra el espacio en el que se desplaza y el vertical el tiempo que transcurre durante sus viajes. Los momentos de estancia (en que permanece fija), denominados estaciones, se presentan en amarillo y los modos en colores (autobús en rojo, caminata en verde y metro en azul).

"Sofía vive en el centro de Colina, en el área más poblada y consolidada de la comuna. Está separada y su hijo Daniel tiene 14 años. Arrienda una casa en una villa cerca al principal supermercado en el centro de Colina por $\$ 100.000^{9}$. Sin embargo, es propietaria de un departamento cerca a la cárcel de Colina, pero no quiere vivir allí: "allá se fue poniendo malo... como queda cerca de la cárcel, los familiares se fueron yendo pa' allá... mucho tráfico, drogas, malo muy malo, si hasta disparos se escuchan... tenía que vivir encerrada, si prácticamente llegaba solo a dormir" (Sofía). Ahora Sofía arrienda, y entre lo que logra sacarle a su departamento y un poco más queda cubierta. Además, su villa queda frente al colegio de su hijo, por lo que se ahorra un pasaje en colectivo ${ }^{10}$ diario, cosa para ella es muy importante. Su mayor preocupación es su hijo, e intenta acomodar su trabajo, acompañarlo a hacer sus tareas y asegurarse para que él no esté solo en las tardes, evitando que se enfrente a la droga en los alrededores.

Para disponer de esta flexibilidad horaria desde hace unos 10 años que trabaja de lunes a sábado como reponedora en dos supermercados en Independencia, comuna ubicada en el peri-centro de la ciudad de Santiago (Ver Figura $\mathrm{N}^{\circ} 2$ ). Su labor consiste en ordenar $\mathrm{y}$

\footnotetext{
9 Alrededor de US\$210

10 Taxi compartido con destinos fijos.
} 
reponer papeles higiénicos y toallas de papel. Ella está contratada por una empresa subcontratista, pudiendo trabajar en más supermercados si desea o ampliar los productos, pero para su situación actual, con dos supermercados y esos productos es justo lo que le sirve. Su horario es relativo "es que llevo hartos años, así que me conocen, nadie me controla, yo llego y hago mi trabajo no más, depende de mí cuanto me demore" (Sofía).

Normalmente Sofía sale de su hogar a las 8:00 u 8.30, dependiendo si ese día llega o no mercadería, lo que significa un poco más de trabajo y llega a Independencia a las 9:00. Alrededor de las 14:00 o 15:00 vuelve a Colina. Sofía gasta diariamente $\$ 3.000^{11}$ en locomoción colectiva. Toma el bus expreso que cuesta $\$ 950^{12}$, si se fuese en colectivo serían $\$ 1.400^{13}$ cada viaje. Para su trabajo, "tenís que saber tomar el bus, y tener la plata" gasta mucha plata en micro, "unos $\$ 60.000{ }^{14}$ mensuales, y hay que saber tener esa plata". Dice que el bus casi siempre llega lleno a su paradero, se llena arriba por la cárcel. Muchas veces se va parada. Además que hace mucho calor en invierno, la calefacción es insoportable. En verano el aire acondicionado es más agradable.

Al ser miércoles, el recorrido será "primero al supermercado de Cardenal Caro, de ahí al de Dorsal". El bus baja por la carretera General de San Martín algo Ileno, pero se puede sentar. Es oscuro y sucio, con una puerta adelante y otra atrás. Sofía mira por la ventana, "siempre miro, no me gusta dormir porque cuesta despertar". Mientras para en un peaje, donde el bus toma más pasajeros, cuenta que más temprano el bus se va más Ileno y que no debería parar en el camino, rompiendo la idea de expreso, pero que lo hace igual. El paisaje es una mezcla de industrias, campo, carretera y cerros. Sigue la carretera hasta Independencia y al poco andar se baja en la calle Cardenal José María Caro; solo tomó 25 minutos llegar. Cruza la Avenida Independencia y camina por Cardenal Caro. En la esquina para a comprar un cigarrillo suelto, y sigue

\footnotetext{
11 Alrededor de US\$6

12 Alrededor de US\$2

13 Alrededor de US\$3

14 Alrededor de US\$126
}

conversando. A las dos cuadras se encuentra con un pequeño supermercado. Ella debe entrar por atrás del supermercado.

A las 10:30 Sofía sale de la bodega, ahora con otra ropa, la de trabajo, cambiando sus jeans ajustados y polera de color por un negro atuendo. Cruza la calle y espera en el paradero y a las 10:40 toma el recorrido B21 "podría tomar la 11 pero me deja medio lejos, así que prefiero esperar a la B21... A donde vamos es medio peligroso, así que prefiero esperar". La micro es de las amariIlas remozadas para Transantiago ${ }^{15}$, de esas ruidosas y destartaladas. Sofía habla de lo peligroso de la Chimba, cuenta historias de crónica policial. La micro dobla nuevamente y en calle Guanaco se baja y camina una cuadra hasta el supermercado, el recorrido no dura más de 10 minutos atravesando casas bajas y grises. Pasa por la entrada a las bodegas y frente a un Teletrak ${ }^{16}$, cuenta cómo los ebrios colonizan este lugar aumentando aún más el peligro y su miedo. Dentro del recinto hay varios negocios pequeños, otros tantos locales vacíos. Para en un bazar a comprar otro cigarrillo suelto y dulces, lo prende y se sienta en una banca frente a la puerta del supermercado a fumar.

Luego quiere pagar una letra en el centro, así que aún queda recorrido. Cuenta de los peligros de la zona "acá pal $11^{17}$ queda la pura cagá, cierran todo esto (haciendo referencia al recinto completo) con mallas... y eso que está el regimiento acá al frente, la PDI ${ }^{18}$ más abajo y pacos, es muy peligroso, no se puede controlar... si acá hasta los cabros chicos son flaites ${ }^{19}$, los visten como flaites, les cortan el pelo como flaites...". Luego da un giro y, ya más cercanas, cuenta que le diagnosticaron cáncer al útero, hace un año. "menos mal que no se había esparcido, me operaron y listo, con Fonasa ${ }^{20}$, no pagué nada y estuve 17 días en el hospital... ya

\footnotetext{
15 Sistema de transporte público de la ciudad de Santiago

16 Red de locales especializados en la transmisión y apuestas hípicas

1711 de septiembre

18 Policía de Investigaciones

19 Denominación peyorativa para los jóvenes marginales

20 Sistema de salud público chileno
} 
no puedo tener hijos"; me dice que se debe controlar cada cierto tiempo, pero que está bien, se apresura a apagar el cigarrillo y se va dirección a la bodega.

A las 13:43 aparece nuevamente con su atuendo inicial, ya había comprado su cigarrillo y se sienta. Apagando el cigarrillo se pone de pie, habla de su rutina cotidiana, de cómo se levanta más temprano para dejarle cocinado a su hijo si es que no alcanzó en la noche anterior. Cruza la calle y espera en el paradero a la micro 101 o 107 que la llevará hasta el metro Dorsal. No demora en llegar, sube, algo apretada por los escolares y va de pie en la parte amplia del bus oruga, apoyada en la ventana, conversando. Va en dirección al metro Cal y Canto a Hites ${ }^{21}$ a pagar una letra, y de pasadita vitrinear un poco. Al bajar del tren opta por la salida a la calle Puente. Sube por una escalera mecánica y se abre paso entre la multitud que a ella no parece importarle. Camina entre el comercio, entre colores y ruidos, con un potente olor a sangre de las carnicerías del barrio.

Camina por el paseo peatonal junto a gente. Sofía para en algunos comercios para mirar las vitrinas. Lleva su bolso cruzado y agarrado con su mano derecha. Entra a Hites, lo recorre y paga su cuenta.

Sale de la tienda en dirección al terminal. Atraviesa la misma ruta hasta tomar avenida La Paz, caminado por ella el olor a podrido molesta, hay frutas tiradas en el piso, un saco de limones que ya debe llevar una semana ahí y el calor potencia la putrefacción, hay ebrios vagabundos durmiendo a sus pies. Camina rápido, dice que no le gusta mucho por aquí, muestra casonas dañadas por el terremoto, y el olor a orina que le perturba.

En Av. La Paz entra al terminal, viejo, sucio y decadente, así como los buses. Se sube al primer bus, no por casualidad; "me sirve porque dice Lo Pinto Panamericana, es más rápido por acá, porque se evita Independencia". Nuevamente desembolsa $\$ 950$.
Se sienta casi al medio en el bus. El bus no va repleto pero sílleno, nadie de pie. Antes de salir del terminal se sube un joven a vender Super $8^{22}$, un viejo a vender bebidas y otro helados. A las 14:50 el bus sale por avenida La Paz y luego toma la Panamericana.

Sofía, cansada, mira por la ventana, la cierra por el viento, cruza los brazos y sigue mirando. A las 15:40 desciende del bus en la plaza de Colina "me gusta bajarme aquí a la vuelta, hay más sombra en el camino". Llega antes de las 16:00 a ver a su hijo."

Revisando el viaje de Sofía, se puede identificar que su viaje se ve estorbado por varias barreras que debe enfrentar en su movilidad urbana cotidiana (Figura $N^{\circ} 3$ ), las principales barreras están vinculadas con dificultades "organizacionales" y "económicas". Ambas asignan espesura a la experiencia de la movilidad cotidiana, para las cuales Sofía desarrolla estrategias y tácticas que están centradas en resolver estas dificultades.

Las barreras organizacionales están vinculadas al hecho de ser madre soltera, y tener que estar ella al cargo del cuidado de su hijo. Esto genera que desarrolle una serie de estrategias que le permitan cumplir con la tarea de cuidar de su hijo y evitar que este quede expuesto a situaciones negativas cuando ella está fuera de casa trabajando. En este sentido, existe una serie de sub-barreras vinculadas a la inseguridad y el temor a los otros en la ciudad, siendo la movilidad residencial una estrategia que Sofía ha desplegado para evitar el contacto con su hijo.

Las barreras económicas de accesibilidad que debe enfrentar Sofía son de diversas naturaleza y de cierta forma dan cuenta de la precarización de la calidad de vida en la cual se desenvuelve, ante las cuales debe generar una serie de estrategias de subsistencia. Un trabajo flexible en una empresa subcontratista, donde la práctica de movilidad sirve como un capital de trabajo que diariamente ella debe movilizar para desplegar su trabajo, y una serie de barreras económicas, vinculadas al gasto excesivo en transporte público debi-

\footnotetext{
22 Golosina
}

21 Tienda comercial 
Figura $\mathrm{N}^{\circ} 3$

Espesura de barreras de accesibilidad de Sofía

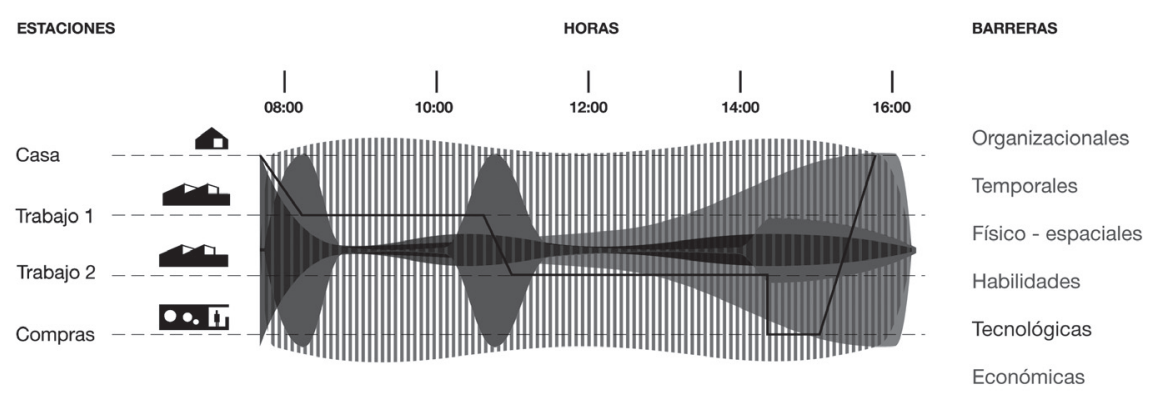

Fuente: Elaboración propia.

do a los monopolios del transporte que aún dominan el negocio en las zonas periféricas de Santiago.

En el caso de Sofía, las barreras físicoespaciales, no están vinculadas a la distancia que debe recorrer diariamente para acceder al trabajo, sino que están conectadas con las condiciones físico-materiales de los microespacios por los cuales se desplaza diariamente, por ejemplo la mala calidad de los buses, los trasbordos, o los terminales de buses deteriorados, con personas que amenazan su seguridad diariamente. En relación a este punto, es posible reconocer también algunas barreras vinculadas con las habilidades para acceder al transporte público; Sofía reconoce que hay que saber cómo tomar el autobús, es decir desarrollar un saber viajar, aspecto que ha logrado dominar por medio del desarrollo de estrategias y tácticas.

Es interesante también mencionar que las barreras temporales tampoco se encuentran vinculadas con los tiempos de viaje que debe recorrer diariamente, ya que los desplazamientos son relativamente cortos, y de forma general estos no son significados por Sofía diariamente como una dificultad en su viaje. Sin embargo, el tiempo sí se ve afectado por los horarios en los cuales debe estar en el trabajo o en su casa, y por tal motivo, escoge este tipo de trabajo para disponer de más tiempo en su hogar.

A continuación se presenta el caso de Silvia según las barreras de accesibilidad en sus viajes en la extraperiferia en automóvil: ingreso alto (Figura $\mathrm{N}^{\circ} 4$ ).

"Silvia tiene casi 40 años, ha estado casada por más de quince años y tiene tres hijos, la mayor Ximena de 13, Gabriel de 10 años y Matías de 5 años. Viven en Chicureo, Colina al norte de Santiago, en un condominio cerrado de altos ingresos en una casa de unos $300 \mathrm{~m}^{2}$ en un terreno de $5.000 \mathrm{~m}^{2}$ con una piscina y sus respectivos jardines. Sus hijos van al mismo colegio, a unos 3 minutos en auto desde su casa. Silvia trabaja medio tiempo organizando el casino para los trabajadores de la fábrica de su marido en la comuna de Lampa, cerca de Colina. Todos los días, excepto los jueves, sale de su casa antes de las 8:00 a dejar a sus hijos al colegio, vuelve a su casa a organizar su casa con las dos empleadas domésticas que allí trabajan, toma su café y alrededor de las 9:00 sale a trabajar, volviendo antes de las 14:00 para preparar el arribo de sus hijos. Ha organizado el transporte de sus hijos con cuatro otras mamás del condominio, que tienen sus hijos en el mismo colegio y se turnan para recogerlos; los jueves son su día.

Hoy es jueves y es su turno de realizar la recogida. Los niños, ayudados por una de las empleadas puertas adentro, están listos para salir a las 7:45, salen del condominio, conduce durante dos minutos y llegan al colegio a las 7:50. Hoy es un día especial, ya que hoy ha organizado el paseo de curso de kinder de su hijo Matías, y va a llevar a los 12 niños del curso a la fábrica de galletas de su mari- 
Figura $\mathrm{N}^{\circ} 4$

Mapa tiempo espacio Silvia

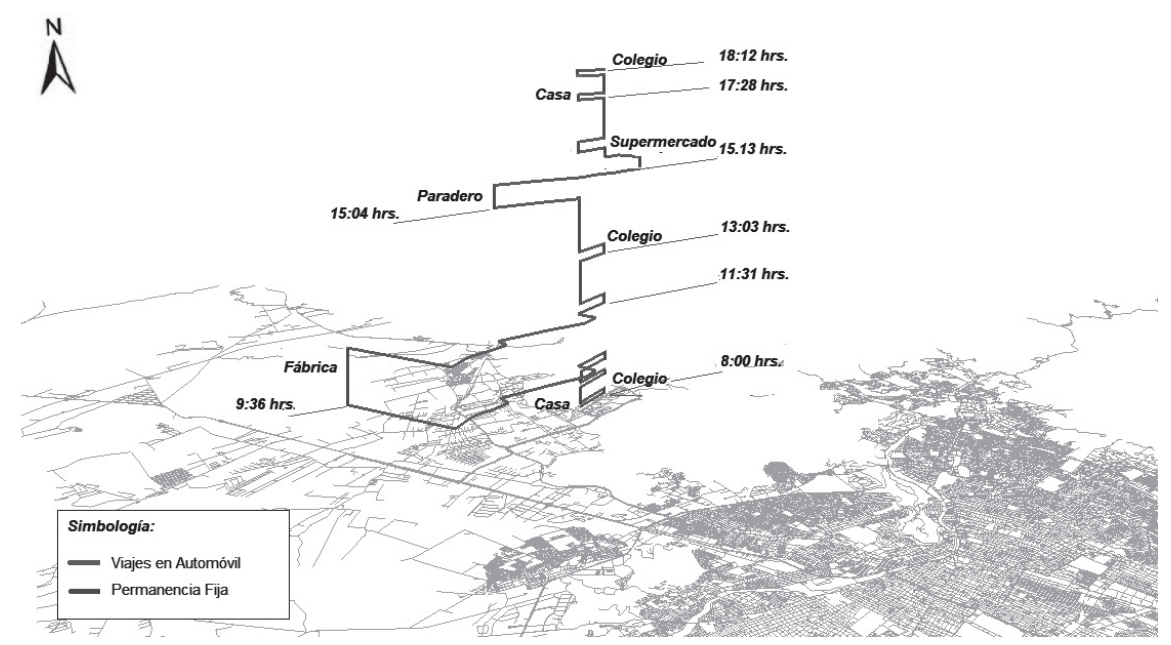

Fuente: Elaboración propia.

do, para que vean el proceso de producción. Matías ha estado emocionado con este paseo hace días. Poco antes de las 9:00, sube a su camioneta $4 \times 4$ y rápidamente Ilega al colegio, donde la esperan otras cuatro mamás. Pronto, la clase de Matías sale en una fila, son todos niños, y todos, al igual que el anfitrión, están sobreexcitados por su destino. Las mamás organizan a los niños en grupos de tres o cuatro en los distintos autos similares al de Silvia; Matías va con su mamá, un compañero y la profesora del curso. En el camino pasa por varios condominios cerrados que son casi imperceptibles desde el camino salvo por las rejas que indican su existencia. Luego pasa por campos, bodegas, pequeñas tiendas, y entra a la autopista con peaje, y en menos de 15 minutos entra a la fábrica con tres grandes galpones dentro. Todos los niños salen de los vehículos y alguien de la fábrica sale a saludar. Los niños, madres y profesoras hacen el recorrido por las galletas de chocolate, vainilla, limón, sus rellenos y las galletas especiales. Una hora y media más tarde, luego de haber comido suficiente masa, galletas y golosinas, parten al colegio otra vez. Cuando llegan, Matías dice estar cansado y decide volver a la casa.

A las 13:00 sale de la casa otra vez para recoger a tres niños del colegio, uno es de la edad de Matías y dos niñitas son más pe- queñas. Les toma de las manos, los sienta en el auto con cinturones y pone las mochilas en la maleta, y maneja por tres minutos de vuelta al condominio, donde deja a cada niño en su casa y se despide de ellos. Una vez en la casa, almuerza y a las 14:30 sale a recoger la segunda camada de cinco niños, que tienen alrededor de ocho y nueve años. Otra vez, los busca en sus clases, y algunos están esperando fuera del colegio con otros niños, caminan al auto, ponen las mochilas en la maleta y conduce de vuelta al condominio. Los deja en las mismas casas donde dejó a los sus hermanos más temprano y otras nuevas y luego va de vuelta a su casa. A las 16:00 una de las empleadas tiene que irse temprano hoy para ir a una reunión en el colegio de su hija en la comuna de Estación Central, en el centro de Santiago, y Silvia la Ileva al paradero cerca de la autopista. Luego va con Matías al supermercado en Chicureo y vuelve a casa. A las 17:00, vuelve al colegio a recoger otra camada de niños, incluyendo a su hijo Gabriel. Repite la misma rutina, y los deja en las mismas casas. A las 18:00, vuelve al colegio a buscar a dos niñas más, una de ellas es su hija Ximena que se quedó a práctica de coro hoy.

Pese a que los viajes no son largos, ha pasado todo el día llevando y trayendo niños hacia y desde el colegio. Silvia dice que este 
Figura $\mathrm{N}^{\circ} 5$

Espesura de barreras de accesibilidad Silvia

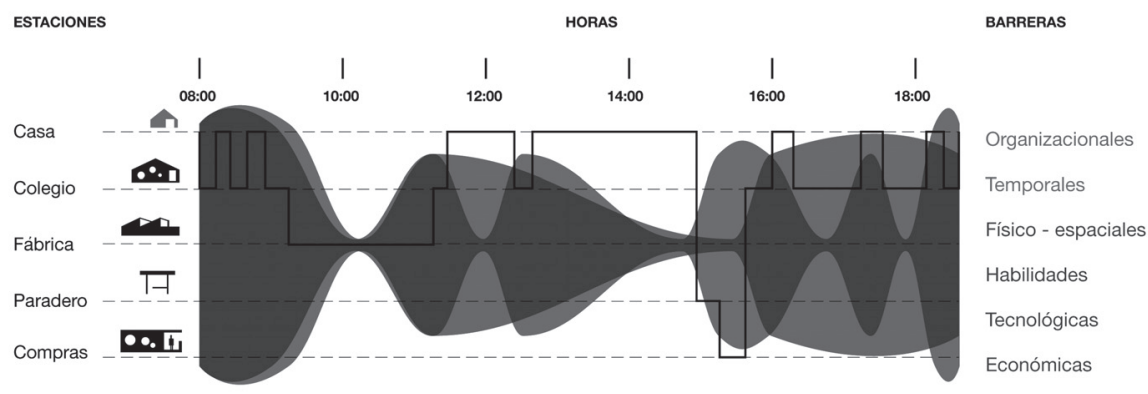

Fuente: Elaboración propia.

es su único día, y que hoy fue un día duro, debido al paseo, pero no le molesta, ya que el resto de la semana esta responsabilidad se encuentra cuidadosamente distribuida entre las otras mamás que se turnan para recoger a los niños. Ella no solo es interdependiente con sus hijos, sino también con las madres de su condominio y sus hijos, así como con las empleadas domésticas que le permiten trabajar y entrar y salir de su casa como desee, mientras que en su casa se limpia, se cocina, se lava la ropa, se plancha y se cuida a los niños mientras ella se mueve por el sector.

El caso de Silvia contrasta con el relato de la experiencia de viaje de Sofía (Figura $N^{\circ}$ 5), aquí las barreras económicas no tienen tanta relevancia como en el caso anterior, sin embargo el rol de género se asemeja ya que debe enfrentar una serie de barreras organizacionales al coordinar sus tiempos para poder movilizar a sus hijos al colegio y a sus actividades extraacadémicas, así como también sus actividades laborales y las demandas de hogar. Las barreras temporales se encuentran vinculadas a un programa de actividades muy denso, los viajes son cortos, pero deben ser realizados en períodos de tiempo muy seguidos uno del otro. En este sentido, resulta interesante identificar las estrategias que genera Silvia con su red de contactos para desplegar una estrategia conjunta que les permita disponer de tiempo libre en la semana, así como con las empleadas domésticas que le permiten flexibilidad horaria, y dejar tiempo para dedicarse a hacer otras cosas.
Las barreras de carácter físico-espacial, económicas y de habilidades, no aparecen significadas por Silvia como aspectos limitantes de sus prácticas de movilidad cotidiana, lo cual podría ser explicado en parte debido a que posee una serie de condiciones que se encuentran garantizadas por su estatus socioeconómico, que le permiten elegir la localización de sus vivienda cerca del colegio de los niños, tener un automóvil para movilizarse entre diversos puntos de la ciudad y disponer del tiempo de sus empleados para poder maximizar su movilidad.

\section{Conclusiones}

El enfoque teórico metodológico propuesto en el presente trabajo permite abordar la exclusión social por medio de la accesibilidad, ampliando la mirada físico-espacial de la accesibilidad; y abriendo una definición diferente, que explica la espesura de las barreras que se enfrentan en la vida cotidiana de las personas en la ciudad. Este enfoque permite develar procesos de exclusión social que mediante otros mecanismos no hubiese sido posible de reconocer, asimismo, permite reconocer las estrategias que se emplean para enfrentar las barreras presentes.

El análisis de las barreras de accesibilidad busca dar cuenta de las diversas limitaciones que deben enfrentar las personas cotidianamente en la ciudad para acceder a la participación social. Comúnmente las barreras de accesibilidad han sido interpretadas a partir de las características físicas que posee el es- 
pacio, especialmente en relación al costo que imprime la distancia sobre el desplazamiento de personas, bienes o servicios desde una localización a otra. Desde este enfoque, la accesibilidad puede ser entendida como una medida cercana a la proximidad espacial o conectividad, donde la condición óptima debería alcanzarse a través de la reducción de la distancia por medio de la intervención del sistema de transporte y/o la disposición de los usos de suelo que dirigen las funciones de la ciudad.

Una propuesta ampliada al análisis de barreras como la que aquí se presenta, a partir de la concepción de espacio como producción social, no niega la importancia de las condiciones físico espaciales declaradas en la propuesta anterior, sino que busca incorporar una interpretación que parte desde el sujeto y las significaciones del mundo que este construye en su tránsito cotidiano. De esta forma, las barreras pueden ser comprendidas desde su espacialidad como aquellas diversas limitaciones que los sujetos encuentran cotidianamente en sus movimientos a través de la ciudad.

Por medio del enfoque de accesibilidad, se devela que el acceso cotidiano de las personas no es solo a actividades sino que atraviesa las redes y los lugares que se apropian en el proceso. En este sentido, sería útil pensar que para generar una accesibilidad efectiva a actividades (empleo, salud, educación, recreación, etc.) se evidencia la necesidad de contar con redes de relaciones sociales que permitan una movilidad interdependiente (Jirón \& Cortés, 2011) como en el caso de Silvia, con su red de vecinas y empleadas domésticas, y la posibilidad de apropiarse de los espacios que se enfrentan en movimiento positiva o negativa como en el caso de Sofía con el bus o los paraderos.

Por otro lado, la accesibilidad por sí sola no tiene características positivas o negativas, su evaluación depende de las implicancias que tiene para las personas en la vida diaria. La desigualdad en la accesibilidad se convierte en un problema cuando no se trata de un acto voluntario, cuando las personas carecen de opciones, cuando se trata de algo obligatorio o cuando las únicas alternativas que quedan son conexiones irregulares, no deseadas o la inmovilidad. La accesibilidad se convierte en problema cuando una mayor posesión de capital genera accesos desproporcionados o cuando las estructuras de la sociedad incrementan las diferencias, privando a algunos de los beneficios que ofrece la sociedad. Lo que devela el estudio es que las barreras no suceden de manera aislada y se genera una cierta espesura en su experiencia.

También, cuando comprendemos la exclusión social como un fenómeno de carácter dinámico, relacional y caracterizado por la multiplicidad de formas en las que la exclusión social puede acontecer, un análisis desde la vida cotidiana, y específicamente desde la movilidad cotidiana y las barreras de accesibilidad, nos permite disponer de herramientas móviles para dar cuenta de este dinamismo, donde las barreras muchas veces coexisten o desaparecen según el tiempoespacio. Por ejemplo, para ambos casos de estudio, las barreras organizacionales repercuten en todas las decisiones de cómo, dónde, y a qué hora moverse. Además inciden en el tipo de trabajo al que optan y, de manera diferente, las condiciones físicas en las que se desplazan. Del mismo modo, esta barrera organizacional se resuelve de mejor o peor manera según los recursos disponibles, como dinero para contratar ayuda o redes sociales para compartir tareas diarias. Las consecuencias de esta accesibilidad diferenciada es que Sofía tiene más limitaciones debido a su condición de mujer madre sola de bajos recursos, a un tipo de trabajo, distante a su lugar de residencia donde existe disponibilidad de trabajo. El viaje al que puede optar también es limitado y las condiciones materiales del mismo muy inferiores que Silvia. En general, Sofía cuenta con opciones limitadas y precarias para hacer funcionar su vida, dejándola fuera de otras oportunidades existentes en la ciudad.

El análisis de la accesibilidad y la forma en que conduce a una conexión o desconexión involuntaria y a relaciones sociales desiguales dentro de prácticas de movilidad involucra estudiar las estrategias que las personas utilizan para acceder y superar las barreras existentes. En el caso de Sofía, esta forma de tener que organizarse hace que desarrolle estrategias prácticamente individuales, mientras que Silvia desarrolla estrategias 
colectivas junto a su red de apoyo. La importancia de comprender estas estrategias es que las personas no se paralizan frente a las múltiples y variadas barreras que enfrentan. Conocer estas estrategias ayudaría a desarroIlar formas de facilitar la accesibilidad en la ciudad.

Las estrategias para enfrentar, desafiar o transgredir los obstáculos que presenta la accesibilidad deben consideran las dificultades que tienen los hogares y las personas. Asimismo, dentro de estas estrategias es posible encontrar la posibilidad de negociar, encontrar, intercambiar o crear algo completamente nuevo. Si bien, muchas estrategias son individuales, la mayoría de las veces tienen implicancias a nivel de hogar, especialmente en términos de organización de rutinas o uso del tiempo y a menudo involucran la participación de terceras personas como amigos o familiares o la contratación de ayuda. En este caso, las estrategias se entienden como una serie de prácticas que se implementan para mejorar o mantener el acceso al tiempo y espacio a la vez que se conserva o aumenta el volumen de capital.

Tal como se puede observar, el enfoque de accesibilidad aquí propuesto permite desplegar una serie de instancias para develar la complejidad en la que se habita en las ciudades como Santiago de Chile. A partir de una comprensión ampliada de la accesibilidad en el marco de la movilidad cotidiana en el tiempo-espacio, se puede desprender que resolver temas de exclusión social van más allá de resolver los temas de eficiencia del transporte o de segregación residencial, las cuales siguen siendo prioritarias, sin embargo se requiere de miradas más amplias e integrales que puedan analizar no solo la conexión sino el acceso efectivo que se tiene.

Tal como sugiere Lucas (2012), este tipo de estudios son aun incipientes a nivel mundial. Sin embargo, son necesarios para avanzar no solo en la comprensión teórica de los fenómenos de exclusión social en ciudades contemporáneas, sino que con el fin de adoptar nuevas metodologías que den cuenta de fenómenos actuales por un lado, y por otro, iniciar discusiones más concretas en cuanto a políticas públicas e intervenciones urbanas.

\section{Referencias bibliográficas}

AVELlanedA, P. Movilidad, Pobreza y Exclusión Social. Tesis Doctoral en Geografía. Barcelona: Universitat Autónoma de Barcelona, 2007.

AXHAUSEN, K.; ZIMMERMAN, A.; SCHONFELDER, S.; FINDSFUSER, G. \& HAUPT, T. Observing the rhythms of daily life: A six-week travel diary. Transportation, 2002, No 29, p. $95-124$.

BARADARAN, S. \& RAMJERDI, F. Performance of Accessibility Measures in Europe. Journal of Transportation and Statistics, 2001, Vol. 4, p. 31 - 48.

CAMAGNI, R. Economía Urbana. Barcelona: Antoni Bosch Editor, 2005.

CARRASCO, J.A. \& MILLER, E.J. The social dimension in action: A multilevel, personal networks model of social activity frequency. Transportation Research, № 43, p. 90-104.

CARRASCO, J.A. Personal network maintenance, face to face interaction, and distance: Studying the role of ICT availability and use. Transportation Research Record: Journal of the Transportation Research Board, 2011, $N^{\circ} 2231$, p. 120-128.

CASS, N.; SHOVE, E. \& URRY, J. Social exclusion, mobility and access. Sociological Review, 2005, Vol. 53, No3, p. 539-555.

CEBOLLEDA, A. Mobility and labour market exclusion in the Barcelona Metropolitan Region. Journal of Transport Geography, 2009, Vol. 17, p. 226-233.

CERDA, J. y MARMOLEJO, C. De la accesibilidad a la funcionalidad del territorio: una nueva dimensión para entender la estructura urbano-residencial de las áreas metropolitanas de Santiago (Chile) y Barcelona (España). Revista de Geografía Norte Grande, 2010, Nº 46, p. $5-27$.

CHURCH, A.; FROST, M. \& SULLIVAN, K. Transport and social exclusion in London. Transport Policy, 2000, Vol. 7, No 3, p. 195-205. 
CLAVAL, P. El Enfoque Cultural y las Concepciones Geográficas del Espacio. Boletín de la A.G.E., 2002, № 34, p. 21-39.

CRESSWELL, T. Mobilities I: Catching up. Progress in Human Geography 2010, Vol. 35, No 4, p. 550-558.

ELLIOT, A. \& URRY, J. Mobile Lives. Routledge: Abingdon, 2011.

FARRINGDON, J. The new narrative of accessibility: its potential contribution to discourses in (transport) geography. Journal of Transport Geography, 2007, № 15, p. 319330.

FLAMM, M. \& KAUFMANN, V. Operationalising the Concept of Motility: A Qualitative Study. Mobilities, 2006, Vol. 1, No 2, p. 167189.

GALLASTEGUI, J. Espacios para una geografía Social, Humanista y Crítica. Valparaíso: Ediciones Facultad de Humanidades, Universidad de Playa Ancha, 2009.

GREGORY, D. Teoría Social e Geografía Humana. In: GREGORY, D.; MARTIN, R. y SMITH, G. Geografia Humana: Sociedade, Espaço e Ciência Social. Río de Janeiro: Jorge Zahar Editor, 1995, p. 90 - 122.

GRIECO, M. \& MCQUAID, R. Editorial Gender and transport: An editorial introduction. Research in Transportation Economics, 2012, Vol. 34, № 1, p. 1-2.

GRIECO, M.; PICKUP, L. \& WHIPP, R. Gender, transport and employment: the impact of travel constraints. Gower: Aldershot, 1989.

GUTIÉRREZ, A. Movilidad y Acceso: Embarazo y Salud Pública en la Periferia de Buenos Aires. Resumen extendido. XV CLATPU, Marzo de 2009, Buenos Aires.

HÄGERSTRAND, T. What about people in regional science? Papers in Regional Science, 1970, Vol. 24, No 1, p. 7-21.

HÄGERSTRAND, T. Space, Time and Human Conditions. In: KARLQVIST, A.; LUNDQVIST, L. \& SNICKAR, F. Dynamic Allocation of Urban Space. Stockholm: Saxon House, 1975, p. 3-14.

HÄGERSTRAND, T. Diorama, Path and Project. Tijdschrift voor Econ. en Soc. Geografie, 1982, Vol. 73, No 6, p. 323-339.

HAGERSTRAND, T. ¿Qué hay acerca de las personas en la Ciencia Regional? Serie Geográfica Departamento de Geografía Universidad de Alcalá de Henares, 1991, N 1, p. $93-110$.

HANSON, S. \& HANSON, P. Gender and Urban Activity Patterns in Uppsala, Sweden. Geographical Review, 1980, Vol. 70, № 3, p. 291-299.

HANSON, S. \& HANSON, P. The TravelActivity Patterns of Urban Residents: Dimension and Relationships to Sociodemographic Characteristics. Economic Geography, 1981, Vol. 57, No 4, p. 332-347.

HANSON, S. Gender and mobility: new approaches for informing sustainability. Gender, Place and Culture, Vol. 17, № 1, 2010, p. 5-23.

HARVEY, D. Urbanismo y desigualdad social. México: Siglo Veintiuno. 1977.

HIGUERAS, A. Teoría y Método de la Geografía. Introducción al análisis Geográfico Regional. Zaragoza: Prensas Universitarias de Zaragoza, 2003.

HINE, J. \& MITCHELL, F. Better for Everyone? Travel Experiences and Transport Exclusion. Urban Studies, 2001, Vol. 38, № 2, p. 319-332.

HINE, J. \& GRIECO, M. Scatters and clusters in time and space: implications for delivering integrated and inclusive transport. Transport Policy, 2003, № 10, p. 299-306.

JIRÓN, P. Mobility on the Move: Examining Urban Daily Mobility Practices in Santiago de Chile. PhD Thesis. London: London School of Economics, 2009.

JIRÓN, P. On becoming 'la sombra/the shadow'. In: BÜSCHER, M.; URRY, J. \& WIT- 
CHGER, K. Mobile Methods. Abingdon: Taylor \& Francis Books, 2010, p. $36-53$.

JIRÓN, P. Technology and Technicians Out of Control: The Implementation of Transantiago From a Daily Mobility Point of View. In: VANNINI, P.; BUDD, L.; FISKER, C.; JIRON, P. \& JENSEN, O. Technologies of Mobility in the Americas, Intersections in Communications and Culture: Global Approaches and Transdisciplinary Perspectives. New York: Peter Lang Publishing, 2012, p. 255 - 277.

JIRON, P. e ITURRA, L. Momentos Móviles: Los lugares móviles y la nueva construcción del espacio público. Revista Arquitecturas del Sur, 2011, No 39, p. 44-57.

JIRON, P. \& CORTÉS, S. Mobile relations, mobile shadows. Understanding contemporary urban daily living through shadowing techniques. In: International Workshop: The Everyday Life of Multi-Local Families. Concepts, Methods and the Example of PostSeparation Families, October 20 - 21 of 2011, Munich.

JIRÓN, P.; LANGE, C. y BERTRAND, M. Exclusión y desigualdad espacial: Retrato desde la movilidad cotidiana. Revista del INVI, 2010, Vol. 25, No 68, p. 15-57.

JONES, P. \& LUCAS, K. The social consequences of transport decision-making: clarifying concepts, synthesising knowledge and assessing implications. Journal of Transport Geography, 2012, Vol. 21, p 4-16.

JOUFFE, Y. y LAZO, A. Las prácticas cotidianas frente a los dispositivos de movilidad. Aproximación política a la movilidad cotidiana de las poblaciones pobres periurbanas de Santiago de Chile. EURE, 2010, Vol. 25, $\mathrm{N}^{\circ} 108$, p. 29-47.

KARST, T.; GEURS, B. \& WEE, V. Accessibility evaluation of land-use and transport strategies: review and research directions. Journal of Transport Geography, 2004, № 12, p. $127-140$.

KAUFMANN, V. \& JEMELIN, C. La motilité, une forme de capital permettant d'éviter les irréversibilités socio-spatiales? Espaces et sociétés aujourd'hui. En: Colloque de Rennes, 21-22 October of 2004, Rennes.

KAUFMANN, V.; BERGMAN, M. \& DOMINIQUE, J. Mobility: Mobility as Capital. International Journal of Urban and Regional Research, 2004, № 284, p. 745-756.

KENYON, S. The 'accessibility diary': Discussing a new methodological approach to understand the impact of Internet use upon personal travel and activity participation. Journal of Transport Geography, 2006a, No 14, p. 123-134.

KENYON, S. Reshaping Patterns of Mobility and Exclusion? The Impact of Virtual Mobility upon Accessibility, Mobility and Social Exclusion. In: SHELLER, M. \& URRY, J. Mobile technologies of the city. Abingdon: Routledge, 2006b, p. 102- 120.

KENYON, S.; LYONS, G. \& RAFFERTY, J. Transport and social exclusion: investigating the possibility of promoting inclusion through virtual mobility. Journal of Transport Geography, 2002, Vol. 10, № 3, p. 207-219.

KENYON, S.; RAFFERTY, J. \& LYONS, G. Social Exclusion and Transport in the UK: A Role for Virtual Accessibility in the Alleviation of Mobility-Related Social Exclusion. Journal of Social Policy, 2003, Vol. 32, No 3, p. 317 338.

KJÆERULFF, A. Motility - finding a way to mobility attitude and behavior. Annual Transport Conference at Aalborg University, 2011, Aalborg.

KUSENBACH, M. Street Phenomenology. The Go-Along as Ethnographic Research Tool. Ethnography, 2003, Vol. 4, No 3, p. 455-485.

KWAN, M.-P. \& LEE, J. Geovisualization of Human Activity Patterns Using 3D GIS: A Time-Geographic Approach. In: GOODCHILD, M.F. \& JANNELLE, D.G. Spatially Integrated Social Science: Examples in Best Practice. Oxford: Oxford University Press, 2003, p. $48-66$.

KWAN, M.-P. Introduction: feminist geography and GIS. Gender, Place and Culture, 2002, Vol. 9, No 3, p. 261-262. 
KWAN, M.-P.; JANELLE, D. \& GOODCHILD, M. Accessibility in space and time: A theme in spatiality integrated social science. Journal of Geographical Systems, 2003, № 5, p. 1-3.

LATHAM, A. Researching and Writing Everyday Accounts of the City. An introduction to the diary-photo diary-interview method. In: KNOWLS, C. \& SWEETMAN, P. Picturing the Social Landscape: Visual Methods and the Sociological Imagination. London: Routledge, 2004, p. 117-131.

LAW, R. Beyond women and transport: towards new geographies of gender and daily mobility. Progress in Human Geography, 1999, Vol. 23, No 4, p. 567-588.

LAZO, A. Transporte, movilidad y exclusión. El caso de Transantiago en Chile. Scripta Nova Revista Electrónica de Geografía y Ciencias Sociales, 2008, Nº 270 (45), Vol. XII. Disponible en Internet: http://www.ub.edu/ geocrit/sn/sn-270/sn-270-45.htm

LEFEBVRE, H. A revolução urbana. Belo Horizonte: Ed. UFMG, 1999.

LEFEBVRE, H. El derecho a la ciudad. Barcelona: Ed. Península, 1969.

LENNTORP, B. Sobre el comportamiento, la accesibilidad y la producción. Serie Geográfica, 1991, №1, p. 119 - 130.

LENNTORP, B. Time-geography - at the end of its beginning. Geojournal, 1999, $\mathrm{N}^{\circ}$ 48, p. $155-158$.

LUCAS, K. Providing transport for social inclusion within a framework, Transportation Research, 2006, № 40, p 801-809.

LUCAS, K. Transport and social exclusion: Where are we now? Transport Policy, 2012, $\mathrm{N}^{\circ} 20$, p. 105-113.

MANSILLA, P. Autopistas, accesibilidad y desigualdad social: el impacto de la red de autopistas concesionadas sobre la dimensión temporal de las prácticas de movilidad en Santiago de Chile. Revista Geográfica de América Central, 2011, Vol. 2, No 47, p. 1- 12.
MILLER, H. Measuring Space-time Accessibility Benefits within Transportation Networks: Basic Theory and Computational Procedures. Geographical Analysis, 1999, № 31, p. $187-212$.

MILLER, H. A Measurement Theory for Time Geography. Geographical Analysis, 2005a, No 37, p. 17-45.

MILLER, H. Place-based Versus Peoplebased Accessibility. In: LEVINSON, D. \& KRIZEK, K.J. Access to Destinations. London: Elsevier, 2005b, p. 63-89.

MILLER, H. Social Exclusion in Space and Time. Moving through nets: The Physical and Social Dimensions of Travel. In: AXHAUSEN, K. W. Selected papers from the $10^{\text {th }}$ International Conference of Travel Behaviour Research. London - UK: Elsevier, 2006, p. 353-380.

MIRALLES, C. Ciudad y transporte: El binomio imperfecto. Barcelona: Ariel, 2002.

OHNMACHT, T. Mapping Social Networks in Time and Space. Zurich: Institute for Transport Planning and System ETH Zurich, 2006.

PRESTON, J. \& RAJE, F. Accessibility, mobility and transport-related social exclusion. Journal of Transport Geography, 2007, Vol. 15, p. 151-160.

RAMÍREZ, B. La Geografía Regional: Tradiciones y Perspectivas Contemporáneas. Investigaciones Geográficas, 2007, № 64, p. 116-133.

SHELLER, M. \& URRY, J. The new mobilities paradigm. Environment and Planning, 2006, No38, p. 207-226.

SHOVE, E. Rushing around: coordination, mobility and inequality. In: ESRC Mobile Network Meeting, October of 2002, London.

VARELA GARCÍA, F. Experiencias sobre los cálculos de accesibilidad mediante SIG. En: CONESA GARCÍA, Y.; ÁLVAREZ ROGEL, Y. y GRANELL PÉREZ, C. El empleo del SIG y la Teledetección en la Planificación Territorial. Murcia: EDITUM, 2004, p. 343-358. 